\title{
Team regulation, regulation of social activities or co-regulation: Different labels for effective regulation of learning in CSCL
}

\author{
Nadira Saab
}

Received: 15 December 2011 / Accepted: 23 December 2011 /

Published online: 9 February 2012

C The Author(s) 2012. This article is published with open access at Springerlink.com

\begin{abstract}
Computer-supported collaborative learning (CSCL) is an approach to learning in which learners can actively and collaboratively construct knowledge by means of interaction and joint problem solving. Regulation of learning is especially important in the domain of CSCL. Next to the regulation of task performance, the interaction between learners who work in a CSCL environment needs to be regulated as well. Despite its importance, the regulation of learning in CSCL has received relatively little attention in research. In the contributions of this special issue different labels are used for various forms of regulation of learning during CSCL. During collaborative learning, the regulation of activities can take place at different levels of social interaction: the individual level, the dyadic level, and the group level. Regulative activities of all three levels are presented in the three studies. All studies have investigated whether the use of regulative activities affected performance, and have found that regulation at the dyadic and/or group level was positively related to group performance. In sum, these three contributions provide a constructive overview of the role of regulation of the (collaborative) learning process in CSCL, both in terms of the impact of regulation on learning processes and learning results as well as the influence of different kinds of support on the regulation of collaborative learning.
\end{abstract}

Keywords Metacognition $\cdot$ CSCL $\cdot$ Regulation

Computer-supported collaborative learning (CSCL) is an approach to learning in which learners can actively and collaboratively construct knowledge by means of interaction and joint problem solving (Van der Linden et al. 2000). This problem solving process consists of different regulative phases: orientation, planning, execution, and evaluation (De Jong et al. 2005; Winne 2005). Problem solving in the context of CSCL is an example of higher order cognitive functioning and requires learners to control and regulate their thoughts and actions. This form of cognitive control or working method, referred to elsewhere as metacognitive skilfulness, is needed for optimal learning (Veenman et al. 1997). This working method

N. Saab $(\bowtie)$

Leiden University, Wassenaarseweg 52, 2333 AK Leiden, the Netherlands

e-mail:nsaab@fsw.leidenuniv.nl 
consists of regulative activities that support the learning process. With these regulative activities, learners can manage their learning, solve problems, and acquire skills and knowledge in different learning domains (Schunk and Zimmerman 1994).

Regulation of learning is especially important in the domain of CSCL, (Erkens et al. 2005). The tasks in CSCL are often complex with little structure and contain open-ended problems with several paths leading to different correct answers (De Jong et al. 2005; Salovaara 2005). Furthermore, in a CSCL learning situation compared to a classroom learning situation, no teacher is present to provide learners with regulative guidance (Azevedo et al. 2004; De Jong et al. 2005). Learners have to regulate their learning process by themselves and have to apply different regulative activities at the right moment. In addition, in a CSCL environment, learners communicate through means of computer-mediated communication (CMC), which often implies that gestures and other non-verbal signs are absent. This makes it necessary to formulate and explicate messages more precisely (Henri 1992), including messages regarding the regulation of the learning process.

Next to the regulation of task performance, the interaction between learners who work in a CSCL environment needs to be regulated as well (Jermann and Dillenbourg 2008; Erkens et al. 2005). Learners have to coordinate their collaboration to reach a common goal (i.e., solving the problem at hand), for example, by asking each other monitoring questions such as "Do you understand what I mean?" (Hmelo-Silver and Barrows 2008). Both regulation of task performance and regulation of the collaboration process are important for effective CSCL.

Most of the time, learners are working independently during CSCL, which means that they do not receive the guidance teachers can usually offer in a classroom. However, the CSCL learning environment can provide scaffolding for different aspects of the learning process. The environment can, for example, provide measures that support the regulation process (Soller et al. 2005), the discovery learning process (De Jong 2006), or the communication process (Saab et al. 2007).

Despite its importance, the regulation of learning in CSCL has received relatively little attention in research (Dillenbourg et al. 2009). With this special issue, a contribution is made to this field of research. This special issue focuses on the regulation of task performance as well as collaboration in CSCL learning. Furthermore, the CSCL environment and its potential to support the collaborative learning process will be discussed, and possible effects of different kinds of support of the regulation of the collaborative learning process will be described. The contributions will explore these issues from different perspectives.

The first (Saab et al. 2011) and second study (Janssen et al. 2010) both focus on inquiry tasks in a collaborative learning environment. Both contributions focus on the relation between regulating task performance and regulation of collaborative processes, in addition to the relation between regulative processes and group performance. Saab and colleagues investigate the possible influence of different kinds of support of the collaborative inquiry learning process on task and team regulation. Saab and colleagues also examine whether regulation of collaborative learning influences group performance.

Janssen and colleagues use data from three studies to explore the same relations as Saab et al., but use a different coding scheme. Moreover, the students participating in the study of Saab et al. work in the domain of physics, whereas the students participating in the study of Janssen et al. work on a task for the subject of history. Janssen et al. investigate whether regulating task performance and regulating collaboration are intertwined or separate processes.

Lajoie and $\mathrm{Lu}$ (2011) report a study which investigates the effect of support measures on co-regulation of learning. Whereas the first two contributions investigate both the regulation 
of task performance and collaborative processes, Lajoie and Lu focus only on the regulation of collaborative processes, which they call co-regulatory strategies. They investigate collaborative decision-making in the context of simulated emergencies that mimic the types of decision-making that is needed by medical teams in life-threatening situations. This study is a good example of the way in which a CSCL approach can enhance group discourse through the use of tools that support co-regulation.

\section{Differentiating between processes of regulation in CSCL}

In this issue different labels are used for various forms of regulation of learning during CSCL. Saab et al. distinguish task and team regulation. Task regulation includes the cognitive activities that are aimed at regulation of the task at hand. Orientation on the task, monitoring of the task and evaluation of the task belong to this category. Team regulation on the other hand is focused on the coordination of the collaboration between students. Planning of activities and monitoring of the team process are part of team regulation.

Janssen et al. distinguish two types of regulative activities during CSCL: the regulation of task-related activities, and the regulation of social activities. By making a distinction between task-related and social activities, the researchers differentiate between activities that are performed in the content space of the collaborative learning process and activities with a social-relational function. An example of task-related activities is asking questions, while monitoring the task can be seen as regulation of task-related activities. Grounding, or establishing shared understanding (Erkens et al. 2006), is an example of a social activity. Monitoring these social processes in a group of collaborators is a way of regulating these social activities.

Lajoie and Lu used a coding scheme developed by Meijer et al. (2006) to label metacognitive activities, such as orientation and planning. They see co-regulation as a form of collaboration that is needed to acquire shared understanding. Co-regulation involves the contributions of multiple group members in order to build up dynamic shared mental models and shared situation awareness which are needed for a successful medical decision process.

During collaborative learning, the regulation of activities can take place at different levels of social interaction: the individual level, the dyadic level, and the group level (Iiskala et al. 2004; Iiskala et al. 2011; Hadwin and Oshige 2011; Volet et al. 2009). Individual regulation can be seen as an intrapersonal process which aims at regulating the individual cognitive processes during collaborative learning. Regulating the activities at a dyadic level means that someone in the group is regulating the individual activities of another member. Regulation at the group level can be seen as performing shared activities aimed at regulating the cognitive activities of the group. Regulative activities performed at the dyadic and group level are interpersonal processes.

The studies in this special issue operationalize the regulation of activities in CSCL in different ways. Figure 1 shows the regulative activities presented in the studies presented in this special issue in relation to these levels of social interaction.

The task regulative activities and team regulative activities that Saab et al. describe can take place at the individual level described above. For example, when a student is monitoring his own knowledge by stating that he doesn't understand the question, which is coded as task regulation by Saab et al., the student is regulating the learning process at an individual level. When a student checks whether another member of the group understands the assignment, he is monitoring the cognitive activities of that other member. The latter is coded as team regulation and can be placed at the dyadic level. Shared actions by several 


\begin{tabular}{|l|c|c|c|}
\hline & \multicolumn{2}{|c|}{ Level of social interaction } \\
\hline Saab et al. & Individual & Dyadic & Group \\
& Task regulation & Team regulation \\
\hline Janssen et al. & Regulation and coordination of task related & $\begin{array}{c}\text { Regulation and } \\
\text { coordination of social } \\
\text { activities }\end{array}$ & activities \\
\hline Lajoie \& Lu & Metacognitive & & Co-regulation \\
& activities & & \\
\hline
\end{tabular}

Fig. 1 Regulative activities described in the three studies presented in relation to the social context in which they occur

members of the group, such as planning activities together to collaboratively solve a problem, is regulating the group's cognitive activities and can be placed at the group level.

The regulation and coordination of task related activities in the study of Janssen et al. can take place at both individual and dyadic level. For example, a student can evaluate her own answer to the assignment, as well as the answer of her group member(s). The regulation and coordination of social activities can be performed at the group level. Monitoring the group process is one of these regulative social activities.

The coding scheme Lajoie and $\mathrm{Lu}$ use, is developed by Meijer et al. (2006) to code metacognitive activities of individuals working alone. Because Lajoie and Lu use this scheme to code regulative activities in a CSCL setting, these regulative activities can have a collaborative character even though they are performed at an individual level. For example, when a student agrees with another student ('I agree'), Lajoie and Lu would code this utterance as a monitoring activity, i.e. claiming (partial) understanding. This is a regulative activity at the individual level in a social setting. However, with this coding scheme it is not possible to code regulative activities at a dyadic level. The researchers describe processes of co-regulation as collaborative activities that enhance the building of shared representations or grounding. Co-regulation can be placed at the group level, since in this process multiple partners perform regulative activities aimed at establishing common ground. Lajoie and Lu describe how co-regulation processes occur in their study during CSCL.

As can be seen in Fig. 1, regulative activities of all three levels are presented in the three studies. All studies have investigated whether the use of regulative activities affected performance, and have found that regulation at the dyadic and/or group level was positively related to group performance. Saab et al. found in one condition that team regulation affected the learning results of the group. Janssen et al. found that regulation of social activities positively affected group performance. Lajoie and Lu discovered that co-regulation led to shared understandings with effective patient management as a result. Based on the results of these studies, it can be concluded that the regulation of activities, labelled as team regulation, regulation of social activities and co-regulation are imported for successful collaboration.

The studies of Saab et al. and Lajoie and $\mathrm{Lu}$ provide insight into the way in which different forms of scaffolds or technology in CSCL can influence the use of regulative activities during the collaborative learning process. Taken together, these three contributions provide a constructive overview of the role of regulation of the (collaborative) learning 
process in CSCL, both in terms of the impact of regulation on learning processes and learning results as well as the influence of different kinds of support on the regulation of collaborative learning. This special issue can serve as a starting point for future studies that investigate the role of regulation of learning in CSCL.

Open Access This article is distributed under the terms of the Creative Commons Attribution Noncommercial License which permits any noncommercial use, distribution, and reproduction in any medium, provided the original author(s) and source are credited.

\section{References}

Azevedo, R., Cromley, J. G., \& Seibert, D. (2004). Does adaptive scaffolding facilitate students'ability to regulate their learning with hypermedia? Contemporary Educational Psychology, 29, 344-370.

De Jong, T. (2006). Scaffolds for scientific discovery learning. In J. Elen \& D. Clark (Eds.), Handling complexity in learning environments: research and theory (pp. 107-128). London: Elsevier Science Publishers.

De Jong, F., Kollöffel, B., Van der Meijden, H., Kleine Staarman, J., \& Janssen, J. (2005). Regulative processes in individual, 3D, and computer supported cooperative learning contexts. Computers in Human Behavior, 21, 645-670.

Dillenbourg, P., Järvelä, S., \& Fischer, F. (2009). The evolution of research on computer-supported collaborative learning: from design to orchestration. In N. Balacheff, S. Ludvigsen, T. de Jong, A. Lazonder, \& S. Barnes (Eds.), Technology-Enhanced Learning. Principles and products, p. 3-19.

Erkens, G., Jaspers, J., Prangsma, M., \& Kanselaar, G. (2005). Coordination processes in computer supported collaborative writing. Computers in Human Behavior, 21, 463-486.

Erkens, G., Prangsma, M., \& Kanselaar, G. (2006). Coordination processes in computer supported collaborative writing. Computers in Human Behavior, 21, 463-486.

Hadwin, A., \& Oshige, M. (2011). Self-regulation, co-regulation, and socially shared regulation: Exploring perspectives of social in self-regulated learning theory. Teachers College Record, 113(6), 240-264.

Henri, F. (1992). Computer conferencing and content analysis. In A. R. Kaye (Ed.), Collaborative learning through computer conferencint: The Najaden papers (pp. 115-136). New York: Springer.

Hmelo-Silver, C. E., \& Barrows, H. S. (2008). Facilitating collaborative knowledge building. Cognition and Instruction, 26, 48-94.

Iiskala, T., Vauras, M., \& Lehtinen, E. (2004). Socially-shared metacognition in peer learning? Hellenic Journal of Psychology, 1(2), 147-178.

Iiskala, T., Vauras, M., Lehtinen, E., \& Salonen, P. (2011). Socially-shared metacognition within primary school pupil dyad's collaborative processes. Learning and Instruction, 21, 379-393.

Janssen, J., Erkens, G., Kirschner, P. A., \& Kanselaar, G. (2010) Task-related and social regulation during online collaborative learning. Metacognition and Learning. doi:10.1007/s11409-010-9061-5.

Jermann, P., \& Dillenbourg, P. (2008). Group mirrors to support interaction regulation in collaborative problem solving. Computers and Education, 51, 279-296.

Lajoie, S. P., \& Lu, J. (2011) Supporting collaboration with technology: does shared cognition lead to coregulation in medicine? Metacognition and Learning. doi:10.1007/s11409-011-9077-5.

Meijer, J., Veenman, M. V. J., \& Van Hout-Wolters, B. H. A. M. (2006). Metacognitive activities in tekst-studying and problem-solving: Development of a taxonomy. Educational Research and Evaluation, 12 (3), 209-237.

Saab, N., Van Joolingen, W. R., \& Van Hout-Wolters, B. H. A. M. (2007). Supporting communication in a collaborative discovery learning environment: The effect of instruction. Instructional Science, 35, 73-98.

Saab, N., Van Joolingen, W. R., \& Van Hout-Wolters, B. (2011) Support of the collaborative inquiry learning process: influence of support on task and team regulation. Metacognition and Learning. doi:10.1007/ s11409-011-9068-6.

Salovaara, H. (2005). An exploration of student's strategy use in inquiry-based computer-supported collaborative learning. Journal of Computer Assisted Learning, 21, 39-52.

Schunk, D. H., \& Zimmerman, B. J. (1994). Self-regulation of learning and performance: Issues and educational applications. Hillsdale: Erlbaum.

Soller, A., Martinez Monés, A., Jermann, P., \& Muehlenbrock, M. (2005). From mirroring to guiding: A review of state of the art technology for supporting collaborative learning. International Journal of Artificial Intelligence in Education, 15(4), 261-290. 
Van der Linden, J., Erkens, G., Schmidt, H., \& Renshaw, P. (2000). Collaborative Learning. In P. R. J. Simons, J. van der Linden, \& T. Duffy (Eds.), New learning. Dordrecht: Kluwer Academic Publishers.

Veenman, M. V. J., Elshout, J. J., \& Meijer, J. (1997). The generality vs. domain specificity of metacognitive skills in novice learning across domains. Learning and Instruction, 7, 197-209.

Volet, S., Vauras, M., \& Salonen, P. (2009). Self- and social regulation in learning context: An integrative perspective. Educational Psychologist, 44(4), 215-226.

Winne, P. (2005). A perspective on state-of-the-art research on self-regulated learning. Instructional Science, $33,559-565$. 